\title{
Superficial roughness and flexural strength of glass-infiltrated zirconia based on the FGM concept
}

\section{Paula Vaz, ${ }^{\star}$ Claudia Volpato, ${ }^{* *}$ Óscar Carvalho, ${ }^{* *}$ Bruno Henriques, ${ }^{* *}$ Márcio Fredel, ${ }^{* *}$ Filipe Silva. ${ }^{* * *}$}

*Porto University, Porto, Portugal

${ }^{* *}$ Federal University of Santa Catarina, Florianópolis, Brasil

${ }^{* * *}$ Minho University, Guimarães, Portugal

This study evaluated the roughness and flexural strength of Zirconia subjected to immersion in liquids, glass infiltration and accelerated aging.

After the machining of 120 Y-TZP disks (Prettau Zirkon, Zirkonzahn®, Italy), 20 disks received no treatment (NT), 20 disks were immersed in coloring liquid (A2) and 20 disks in fluorescence liquid $(\mathrm{F})$. The remaining 60 disks were submitted to the same treatments and, soon after, were glass infiltrated (NT+l, $\mathrm{A} 2+\mathrm{l}$ and $\mathrm{F}+\mathrm{I})$ (Figure 1). Ten disks from each group were aged for 4 hours in an autoclave (T1). The disks were analyzed in a rugosimeter and, after polishing, submitted to mechanical testing (B3B). The maximum load $(N)$ values allowed the calculation of a mean biaxial flexural strength $(\mathrm{MPa})$ and the Weibull modulus $(m)$. After fracture, fragments were observed in SEM. Statistical analysis was performed by three-way ANOVA and Tukey HSD test $(\alpha=0.05)$.

The group $A 2+l-T 1$ showed the highest roughness $(0.25 R a)(p=0.01)$, while the $N T+1$ T0 group had the lowest $(0.182 \mathrm{Ra})$, similar to the non-aged groups $(\alpha=0.05)$. Laboratory treatment with liquids, infiltration and an aging protocol influenced the flexural strength behavior of the groups $(p<0.001)$. The NT and A2-T0 groups had the highest mean values of flexural strength (1.713 and $1852.02 \mathrm{MPa}$ ), and the F-T1 group revealed the lowest mean (729.64 MPa). The groups reduced their resistance after aging, except for the NT+l and $\mathrm{F}+\mathrm{I}$ groups. The Weibull moduli varied from 6.5 to 7.5 , and the A2-T0 group had the largest module (7.5). The micrographs suggested that the $F$ group presented higher porosity after sintering (Figure 2), followed by infiltrated disks.

The infiltration helped to protect the surface of the zirconia samples, but did not prevent surface roughness from increasing, especially in the colored group $(A 2+I)$.
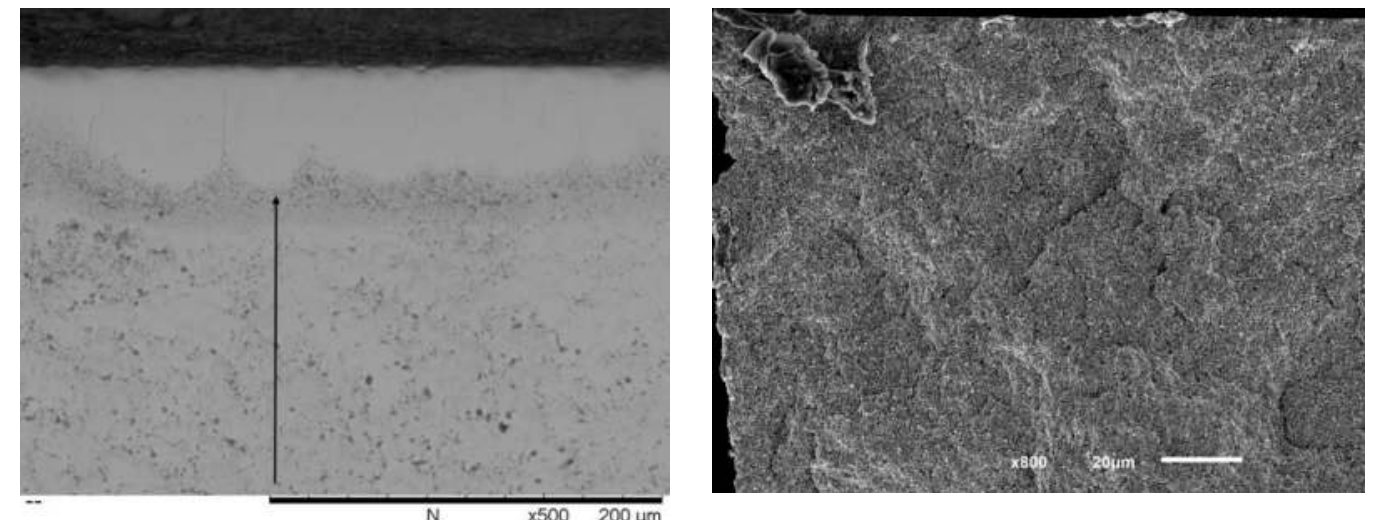

Figure 1. Area infiltrated by glass (arrow). At the top of the specimen, the zirconia sample was not infiltrated. Figure 2. Scanning electron microscopy micrographs (x 800 magnification) of the fracture surface of the $F$ group.
The $A 2+\mathrm{I}-\mathrm{T} 1$ group showed the highest roughness $(0.25 \mu \mathrm{m} \mathrm{Ra})(\mathrm{p}=0.01)$, while the $\mathrm{NT}+\mathrm{I}-\mathrm{T0}$ group had the lowest $(0.182 \mu \mathrm{m} \mathrm{Ra})$, similar to the non-aged groups (Table 1$)$. Immersion in liquids, glass infiltration and aging influenced the flexural strength of the groups $(p<0.001)$ (Table 2). The NT and A2-T0 groups had the highest mean flexural strength (1713 and $1852.02 \mathrm{MPa}$ ), and the F-T1 group had the lowest (729.64 MPa). The groups' resistance decreased after aging, except for the NT+l and F+l groups. The Weibull moduli varied from 6.5 to 7.5 , and the A2-T0 group had the highest module (7.5).

Table 1. Averages and standard deviations of the arithmetic roughness (Ra) according to the aging times (TO and $\mathrm{T} 1$ ) in groups.

\begin{tabular}{|c|c|c|c|c|}
\hline Group & Time & $($ Ra $)$ & Time & (Ra) \\
\hline NT & Oh & $0.195 \pm 0.013^{\mathrm{a}}$ & $4 \mathrm{~h}$ & $0.211 \pm 0.017^{\mathrm{a}, \mathrm{b}}$ \\
NT+l & & $0.182 \pm 0.015^{\mathrm{a}}$ & & $0.185 \pm 0.017^{\mathrm{a}}$ \\
A2 & & $0.206 \pm 0.018^{\mathrm{a}}$ & & $0.201 \pm 0.019^{\mathrm{a}}$ \\
A2+l & & $0.200 \pm 0.015^{\mathrm{a}}$ & & $0.250 \pm 0.017^{\mathrm{b}}$ \\
F & & $0.190 \pm 0.024^{\mathrm{a}}$ & & $0.209 \pm 0.014^{\mathrm{a}, \mathrm{b}}$ \\
F+l & & $0.195 \pm 0.021^{\mathrm{a}}$ & & $0.195 \pm 0.020 \mathrm{a}, \mathrm{b}$ \\
\hline
\end{tabular}

Table 2. Mean biaxial flexural strength, Weibull modulus and confidence intervals for biaxial strength according to the aging times (T0 and T1) in groups.

\begin{tabular}{|c|c|c|c|c|}
\hline Group & Time & $\begin{array}{l}\text { Mean biaxial } \\
\text { strength }(\mathrm{MPa})\end{array}$ & $\begin{array}{l}95 \% \text { Confidence intervals } \\
\text { for biaxial strength (MPa) }\end{array}$ & $\begin{array}{c}\text { Weibull } \\
\text { Modulus (m) }\end{array}$ \\
\hline $\begin{array}{l}\mathrm{NT} \\
\mathrm{NT}+\mathrm{I} \\
\mathrm{A} 2 \\
\mathrm{~A} 2+\mathrm{I} \\
\mathrm{F} \\
\mathrm{F}+\mathrm{I}\end{array}$ & Oh & $\begin{array}{c}1713 \pm 157.35^{\mathrm{a}} \\
973.65 \pm 302.94^{\mathrm{a}} \\
1852.02 \pm 173.21^{\mathrm{a}} \\
1327.29 \pm 95.98^{\mathrm{b}} \\
902.68 \pm 226.11^{\mathrm{c}} \\
1178.32 \pm 179.72^{\mathrm{b}}\end{array}$ & $\begin{array}{c}1391.51-1887.44 \\
514.75-1324.39 \\
1556.71-2238.88 \\
1182.75-1470.69 \\
615.83-1273.39 \\
876.13-1426.98\end{array}$ & $\begin{array}{l}7.4 \\
6.8 \\
7.5 \\
7.1 \\
6.7 \\
7.0\end{array}$ \\
\hline $\begin{array}{l}\text { NT } \\
\text { NT+l } \\
\text { A2 } \\
\text { A2+l } \\
\text { F } \\
F+1\end{array}$ & $4 \mathrm{~h}$ & $\begin{array}{c}1327.86 \pm 182.60^{b} \\
1082.63 \pm 258.47^{b} \\
1418.02 \pm 202.01^{a} \\
1204.62 \pm 95.98^{b} \\
729.64 \pm 189.57^{c} \\
1255.85 \pm 231.09^{b}\end{array}$ & $\begin{array}{c}1031.44-1597.67 \\
437.83-1269.95 \\
1038.55-1626.97 \\
964.52-1637.58 \\
355.18-1000.91 \\
825.94-1614.31\end{array}$ & $\begin{array}{l}7.1 \\
6.9 \\
7.2 \\
7.0 \\
6.5 \\
7.1\end{array}$ \\
\hline
\end{tabular}

* Same letters mean statistically similar behavior $(\alpha=0.05)$.

\section{Background and Aim}

Zirconia have been colored by immersion techniques to simulate teeth color. Metal oxides present in the liquids can act as impurities, influencing their mechanical performance..$^{1,2}$ Zirconia is a material prone to aging, resulting in roughness and decrease in resistance in the medium and long term. ${ }^{3}$ Based on the FGM concept (Functionally Graded Materials), interfaces between zirconia/glazes have been employed, which showed a considerable improvement in the resistance to wear, fracture and fatigue. ${ }^{4,5}$

This study evaluate the roughness and flexural strength of Zirconia subjected to immersion in liquids, glass infiltration and aging. The null hypotheses are that the treatments do not modify the surface patter and flexural strength, and aging is not capable of promoting changes in the properties studied.

\section{Conclusion}

The immersion, as well as infiltration, modified the surface pattern and flexural strength of the groups. Aging increased the roughness and decreased the strength, except in the $\mathrm{NT}+\mathrm{l}$ and $\mathrm{F}+\mathrm{l}$ groups, which confirms that the presence of glass helped to protect the surface from the water action. Although the main objective of the liquids is to obtain a suitable colorimetric behavior, their presence may influence the mechanical properties of the zirconia in the course of time.

This study was supported by a grant (88881.119044/2016-01) from CAPES (Coordination for the Improvement of Higher Education Personnel) in Brazil, and from FCT (Foundation for Science and Technology) in Portugal, with the project reference UID/EEA/04436/2013 by FEDER funds, through the COMPETE 2020 with the project reference POCI-01-0145-FEDER006941, and the project NORTE 01-0145-FEDER-000018.

\section{Methods and Materials}

After the machining of 120 Y-TZP disks (Prettau Zirkon, Zirkonzahn®, Italy), 20 disks received no treatment (NT), 20 were immersed in a coloring liquid (A2, Color Liquid Prettau, Zirkonzahn®, Italy) and 20 were immersed in a fluorescence liquid (Liquid Fluoreszenz, Zirkonzahn®, Italy). The other 60 disks were divided into three groups (NT+l, $\mathrm{A} 2+\mathrm{I}$ and $\mathrm{F}+\mathrm{I}$ ) submitted to the same treatments and, soon after, were glass infiltrated (Vita InCeram S1, VITA $®$ Zahnfabrik, Germany) according to the FGM concept. Ten disks from each group were aged for 4 hours in an autoclave (T1). The disks were analyzed with a roughness meter, polished and submitted to mechanical testing (B3B). The maximum load $(\mathrm{N})$ values allowed calculating the mean biaxial flexural strength $(\mathrm{MPa})$ and the Weibull modulus $(\mathrm{m})$. Statistical analysis was performed by 3-way ANOVA and Tukey's HSD test $(\alpha=0.05)$.

\section{References}

1. Hjerppe $J$ et al. Effect of shading the zirconia framework on biaxial strength and surface microhardness. Acta Odontol Scand 2008; 66:262-7.

2. Orhun E. The effect of coloring liquid dipping time on the fracture load and color of zirconia ceramics. J Adv Prosthodont 2017; 9:67-73.

3. Chevalier $\mathrm{J}$ et al. The tetragonal-monoclinic transformation in zirconia: lessons learned and future trends. J Am Ceram Soc 2009; 92:1901-20.

4. Zhang Y, Kim J.W. Graded structures for damage resistant and aesthetic all-ceramic restorations. Dent Mater 2009; 25:781-90.

5. Zhang Y, Chai H, Lawn BR. Graded structures for all-ceramic restorations. J Dent Res 2010; 89:417-21. 